Portland State University

PDXScholar

5-16-1986

\title{
An Attempt to Reduce Actor-Observer Differences in Attributions
}

Carla A. Green

Portland State University

Follow this and additional works at: https://pdxscholar.library.pdx.edu/open_access_etds

Part of the International and Intercultural Communication Commons, and the Psychology Commons Let us know how access to this document benefits you.

Recommended Citation

Green, Carla A., "An Attempt to Reduce Actor-Observer Differences in Attributions" (1986). Dissertations and Theses. Paper 3705.

https://doi.org/10.15760/etd.5589

This Thesis is brought to you for free and open access. It has been accepted for inclusion in Dissertations and Theses by an authorized administrator of PDXScholar. Please contact us if we can make this document more accessible: pdxscholar@pdx.edu. 
AN ABSTRACT OF THE THESIS OF Carla A. Green for the Master of Science in Psychology presented May 16, 1986.

Title: An Attempt to Reduce Actor-Observer Differences in Attributions.

APPROVED BY MEMBERS OF THE THESIS COMMITTEE:

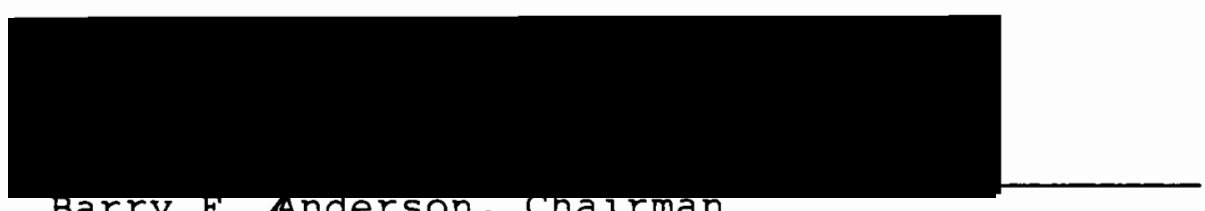
Barry F. Anderson, chalrman

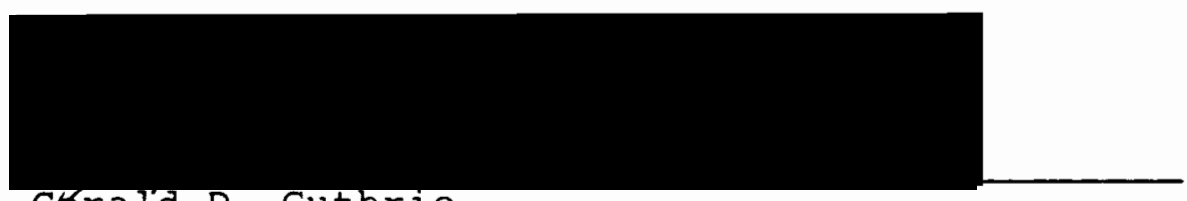
Gerald D. Guthrie

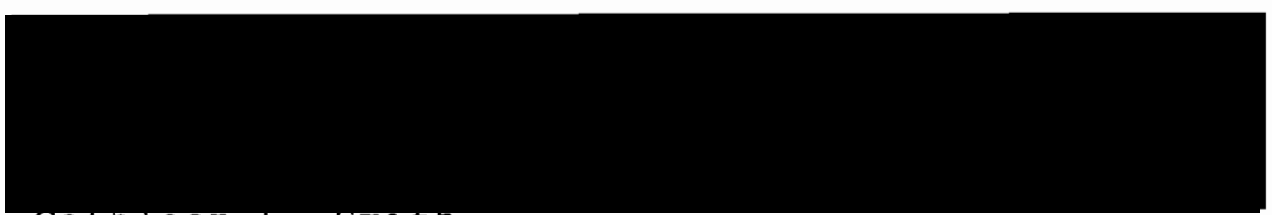

Catnleen L. SmIth

The purposes of this study were (a) to replicate previous research reporting actor-observer differences in subjects' attributions about behavioral causality, and (b) to manipulate the availability of causal information so that those actor-observer differences would be eliminated.

An Availability Balancing List ( $A B L$ ) was designed in an effort to modify subjects' attributions by increasing the availability of possible dispositional and situational causes of behavior. An Attribution survey (AS) assessed 
subjects' dispositional and situational attributions, and was administered to the treatment group after the $A B L$; control-group triads received only the AS. A pre-commitment condition was included in order to determine whether effects of the $A B L$ were due to dissonance-related phenomena.

Subjects were arranged in triads, randomly assigned to a treatment or control group, and asked to interact in a conversation for ten minutes. After the discussion, control subjects filled out the AS, and treatment-condition subjects completed the $\mathrm{ABL}$ and then the AS. Results of the study did not replicate expected actor-observer differences, nor was there any effect of the ABL. Explanations for these results are discussed, as well as suggestions for further research. 


\title{
AN ATTEMPT TO REDUCE ACTOR-OBSERVER \\ DIFFERENCES IN ATTRIBUTIONS
}

by

CARLA A. GREEN

A thesis submitted in partial fulfillment of the requirements for the degree of

\author{
MASTER OF SCIENCE \\ in \\ PSYCHOLOGY
}

Portland State University

1986 
TO THE OFFICE OF GRADUATE STUDIES AND RESEARCH

The members of the Committee approve the thesis of Carla A. Green presented May 16, 1986.
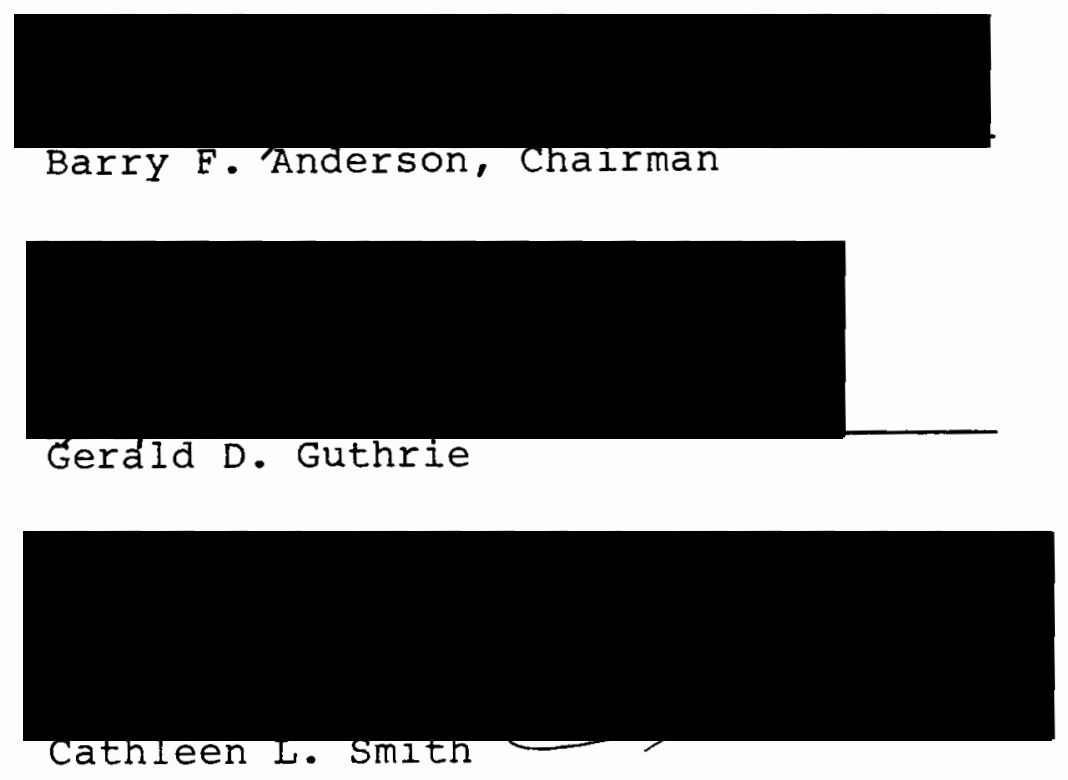

\section{APPROVED :}

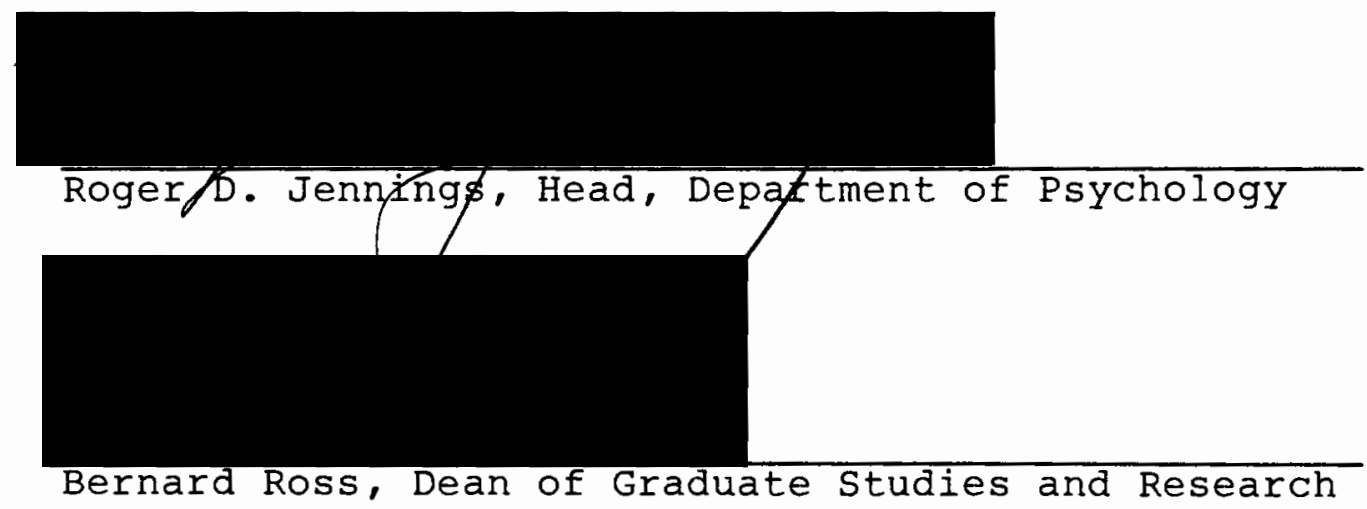




\section{ACKNOWLEDGEMENTS}

I wish to express my gratitude to all members of my thesis committee for providing the innumerable hours of help and support which made it possible to complete this project. Specifically, I want to thank my thesis chairman, Dr. Barry Anderson, for his almost constant availability, unending patience and precious assistance throughout this process. I also wish to thank Dr. Cathleen Smith, whose insight into problems and thoughtful comments provided substantive contributions during the design, implementation and writing stages. To Dr. Gerald Guthrie I owe special thanks for helping me to define my goals for the thesis, consolidate and limit my topic, and particular appreciation for his general support through both my undergraduate and graduate studies at Portland State University. In addition, Dr. Jim Paulson was helpful with statistical procedures during critical periods in the course of the design, and while the data were being analyzed.

Lastly, it would have been impossible to complete this thesis without the support of both friends and family--too many to name--who helped me make it through this sometimes stressful process. 
TABLE OF CONTENTS

PAGE

ACKNOWLEDGEMENTS. . . . . . . . . . . . . . . iii

IIST OF TABLES . . . . . . . . . . . . . . . . vi vi CHAPTER

I INTRODUCTION . . . . . . . . . . . 1

Causes of the Fundamental Attribution

Error ................ . 2

The Fundamental Attribution Error and

the Availability Heuristic . . . . . 4

The Availability Balancing List . . . . 6

The Present Study . . . . . . . . . 10

I I METHOD . . . . . . . . . . . . . 11

Subjects . . . . . . . . . . . . . 11

Materials . . . . . . . . . . 11

Procedure . . . . . . . . . . . 13

II RESULTS . . . . . . . . . . . . 16

IV DISCUSSION . . . . . . . . . . . . . 20

REFERENCES. •. . • . . . . . . . . . . . . . 26

APPENDIX

A Informed Consent Sheet . . . . . . . 29

B Instructions to Participants ........ 31

C Availability Balancing List for Other-Raters . 32

D Availability Balancing List for Pre-

Commitment Other-Raters . . . . . . 37 
APPENDIX

E Availability Balancing List for Self-Raters. . 42

F Attribution Survey for Other-Raters . . . . 47

G Attribution Survey for Pre-commitment

Other-Raters... . . . . . . 50

H Attribution Survey for Self-Raters . . . . . 53

I Personal Data Form . . . . . . . . . 56 


\section{LIST OF TABLES}

TABLE

PAGE

I Types and Colors of Availability Balancing

Lists and Their Target Subjects . . . . . 13

I Results of Discriminant Analysis for Actor-

Observer Differences on all Attribution

Survey Test Items . . . . . . . . . . 18 
CHAPTER I

INTRODUCTION

The purposes of this study were (a) to replicate actorobserver differences in subjects' attributions about behavioral causality, and (b) to manipulate the availability of causal information so that differences in actor-observer attributions would be eliminated.

The fundamental attribution error (FAE) has been defined as "the tendency [on the part of the observer] to attribute behavior exclusively to the actor's dispositions and to ignore powerful situational determinants of the behavior" (Nisbett \& Ross, 1980, p. 31). Ample evidence for the FAE has been generated (Jones, 1979; Jones \& Harris, 1967; Miller, Jones, \& Hinkle, 1981; Nisbett, Caputo, Legant, \& Maracek, 1973; Ross, 1977; Storms, 1973), as well as a variety of explanations for its occurrence (see Fiske \& Taylor, 1984, for a review). There has also been discussion about whether or not this tendency is an error at all (Funder, 1982; Hamilton, 1980; Harvey, Town \& Yarkin, 1981). However, Harvey \& Weary (1984) argue that the controversy surrounding empirical confirmation of the FAE's causes and its status as an error may be of little importance, because it seems clear that whatever the reasons for this tendency, and in whatever situations it occurs, we are dealing with 
a "potent social judgment bias" (p. 432). In other words, whether dispositional factors are or are not more important than situational factors in accounting for behavior, there is a tendency to perceive them as more influential.

Causes of the Fundamental Attribution Error. Heider (1958) proposed what seems to be the "primary cause" (Fiske \& Taylor, 1984) of the FAE when he suggested that people make dispositional attributions because "behavior in particular has such salient properties it tends to engulf the total field" (Heider, 1958, p. 54). In other words, behavior as the most salient feature becomes "figure" in reference to the field or "ground". Nisbett and Ross (1980) believe this is partly because situational factors may tend to be less eye-catching and also less interesting in comparison to active human beings.

This explanation has received support from several studies which manipulated the salience of participating actor subjects, using a variety of different methods. These studies manipulated (a) visual prominence through the use of illumination and movement of the actor (McArthur \& Post, 1977), (b) "solo" status in terms of either race or sex within a group (Taylor, Fiske, Close, Anderson, \& Ruderman, 1979; as cited in Nisbett \& Ross, 1980), (c) the point of view of actors and observers by reversing their visual perspective through the use of videotape (Storms, 1973) and (d) ability of observers to see one of the actors (Taylor \& 
Fiske, 1975). In general, results of these studies indicate that the salience of the actor has a major effect upon observers' judgments about the actor's causal role: The more salient the actor, the more likely he or she is seen as a causal agent, and hence the more probable the dispositional attribution.

From this argument, a further corollary can be derived: If the behavior of the actor is figural for the observer, then the situation should be figural for the actor (what is in his/her perceptual field as opposed to behavior as ground), with resulting situational emphases for selfraters when they pick causal candidates for their own behavior. Einhorn and Hogarth (1986) believe this welldocumented phenomenon occurs for the following reasons:

Note that from the actor's perspective, his or her own traits are standing states, whereas situations are more intrusive and hence (perceived as) more causal. From the observer's perspective, situations are seen as standing states and the dispositions of actors are more intrusive. (p. 5)

Because of these divergent perspectives, Jones (1976) believes that observers have relatively little information available for use when making attributions about actors' behavior except for the behavior's most salient features. But, in the case of the actor, it is likely that he or she will take into account a combination of both personal behavioral history in similar situations, as well as the salience of environmental causes. Because of the more equal consideration of both dispositional and situational factors 
in actors' attributions, it would be easy to conclude that their attributions are closer to the "truth", but this conclusion would most likely be premature (Funder, 1982; Hamilton, 1980; Harvey, Town, \& Yarkin, 1981).

It is interesting to note that, when actors are told to look at their own behavior as others might, and observers are encouraged to empathize with actors, this actorobserver effect can be shifted in the opposite direction for both the actor and observer (Gould \& Sigall, 1977; Regan \& Totten, 1975). This may suggest that behavior can be placed in a larger context (which includes both situational and dispositional constraints) when people empathize with each other, and that when this is possible information is available in addition to that which is most salient.

The Fundamental Attribution Error and the Availability Heuristic. Nisbett and Ross (1980) believe that use of the most salient information by actors and observers as a method for interpreting behavioral causality may be based on mechanisms similar to what Tversky and Kahneman (1974) have termed the "availability heuristic". According to Tversky and Kahneman, people depend on the availability heuristic when they estimate the frequency or probability of an event on the basis of its accessibility during recall (its availability). Nisbett and Ross (1980) define availability as the "accessibility [of objects or events] in the processes of perception, memory, or construction from imagination" ( $p$. 
18). Thus, "When the size of a class is judged by the availability of its instances, a class whose instances are easily retrieved will appear more numerous than a class of equal frequency whose instances are less retrievable" (Tversky \& Kahneman, 1974, p. 1127). In the case of the fundamental attribution error, "what is dominant when one observes another person is that person behaving: the person moves, talks, and engages in other actions that attract attention. Background factors, social context, roles, or situational pressures that may have given rise to the behavior are, by constrast, relatively pallid and dull and unlikely to be noticed when compared to the dynamic behavior of the actor" (Fiske \& Taylor, 1984, p. 74). These factors all contribute to the salience of dispositional as opposed to situational information for the observer, and Tversky and Kahneman (1974) believe that the relative salience of events is one major factor in determining how available they will be for future recall.

The notion that the FAE may be related to the availability heuristic allows us to consider other ways in which the availability of situational as well as dispositional factors may be manipulated. If the FAE is in part a function of the use of only the most available information (in this case dispositional information for observers), then it would seem that increasing the availability of environmental events as potential causal factors should enhance the use of these events or characteristics as adjudged 
causal agents.

If the perceptual salience of the actor for the observer and the environment for the actor is at least partially responsible for actor-observer differences, then interventions designed to reduce these tendencies should seek to make situational stimuli more available for the observer and dispositional stimuli more available for the actor.

Tversky and Kahneman (1974) believe that the availability of information is a function of recall and that recall can be influenced not only by salience but also by the familiarity of the causal information to the observer (familiarity is influenced in part by recent occurrences of the causal agent in action), as well as the imaginability of that information lability to imagine different cases where the event may be causal). With these considerations, it may be possible to construct a task designed to make both situational and dispositional information more familiar and more easily imaginable. This task would intensify memory associations between situational influences and behavioral causes for observers, and between dispositional influences and behavioral causes for actors, thereby making them more readily recalled.

The Availability Balancing List. For designing such a task, two areas of research seemed appropriate to consider: depth of processing, and (b) influences of availability and 
category presentation on causal judgments. Research into how different levels of information processing affect recall has revealed that information processed at the semantic level (in sentences) is better recalled than is information processed at non-semantic levels (in rhymes) (Craik \& Tulving, 1975). This suggests that if subjects are asked to process causal information in sentence form, it might make this information more easily recalled.

From the judgment and decision-making literature came clues which were useful in deciding how to structure and present causal information. Fischhoff, slovic and Lichtenstein, in their 1978 study on the use of fault trees for determining potential causes of a car's failure to start, found that presenting potential causal agents to subjects in explicit functional categories (such as "battery charge insufficient" or "ignition system defective") increased the perceived importance of those categories. For the purposes of the present study, these findings suggested that if subjects were presented with categories divided into smaller segments describing potential causes for behavior (in this case both situational and dispositional factors), their perceptions of the importance of the material in the categories might increase.

In order to attenuate the FAE and its corollary in self-raters, an Availability Balancing List (ABL) was designed to capitalize on both of the above findings: It combined a semantic processing strategy (generating written 
examples) with a guided breakdown (in the form of functional categories i.e., situational and dispositional) of possible causes for behavior. An example of a dispositional category is "The intelligence and/or personal skills of (the rated person)"; an example of a situational category is "The fact that this is an experiment, including the presence of the investigator". Both dispositional and situational explanations for behavior were included in the $A B L$ in an effort (a) to modify the attributions of both other-raters and self-raters, (b) to obtain data on an unbiased instrument, and (c) to reduce demand characteristics (Orne, 1962), i.e., to avoid subjects' perceiving the goal of the experiment and complying with it to please the experimenter.

It could be posited that the $A B L$ might produce its effect (making self-raters' attributions more dispositional and other-raters' attributions more situational) because of processes similar to those found in the study of dissonance phenomena. Dissonance is produced when people engage in behaviors and thoughts which run counter to their belief systems. In such situations, attitudes are often subsequently changed to match these dissonant behaviors and thoughts, and in some cases, subjects cannot even remember their initial attitudes (i.e., their beliefs before counterattitudinal behavior or thoughts were induced) (Bem \& McConnel1, 1970; Wixon \& Laird, 1976). It is possible that mechanisms similiar to these could be involved in changes produced by the $A B L$, because subjects might be generating 
examples which run counter to their beliefs about what causes behavior. However, because the ABL contained categories that reflected both dispositional as well as situational determinants of behavior, it was hoped that by asking subjects to generate examples that illustrated their established beliefs about the causes of behavior as well as alternative causal explanations, counterattitudinal effects would be lessened. In addition, a pre-commitment condition in the study attempted to address attitude change produced by counterattitudinal behavior, by inserting instructions designed to reduce potential dissonance (subjects were told that they could revise their responses later, that they were not final).

To examine these questions, undergraduate students were asked to have short conversations (10 minutes) in triads, for the purpose of getting to know one another. This task was chosen as a partial replication of the "getting acquainted" conversation used by Storms (1973). After the conversation, the treatment-group triads were asked to generate examples of causal agents listed on the ABL. Finally, all triads were asked to answer questions on an Attribution Survey (AS), patterned after the survey used by storms (1973). The survey used a nine-point scale (as did Storms) to assess subjects' attributions to dispositional and situational explanations of the rated person's (either self or other) behavior, the scale points ranging from one as "extremely important" to nine as "extremely 
unimportant." Five dimensions were studied along both situational and dispositional lines, four of which came from the Storms (1973) study. Those from Storms' response measure were (a) friendliness, (b) talkativeness, (c) nervousness, and (d) dominance, and the final dimension (not from Storms) was (e) listening (skills). When the data were tabulated, an overall percentage of situational attributions was calculated for each individual questionnaire. These were the final scores used for comparisons during data analysis.

The Present Study. Several hypotheses were tested in the present study: (a) that observers' attributions about others differ from actors self-attributions (replication of previous research into actor-observer differences), (b) that observers' attributions about others differ from observers' attributions about others in a pre-commitment condition (non-dissonance producing), (c) that the use of the Availability Balancing List has the effect of increasing situational attributions in other-raters and that it may influence dispositional ratings in self-raters, and (d) that the $A B L$ has a differential effect on observers' attributions of others, pre-commitment condition observers' attributions of others, and actors' attributions of self. 
CHAPTER II

METHOD

Subjects. Subjects were 32 male and 46 female undergraduate students in Introductory Psychology and Human Development courses at Portland State University, ranging in age from 18 to 44 years. Subjects were formed into 26 mixed-sex triads on the basis of scheduling convenience.

Materials. Initial materials consisted of a page requesting informed consent for participation in a research study (see Appendix A) and Instructions to Participants, patterned after those in storms' (1973) study, which briefly describe the form the conversation between the three participants should take (see Appendix B).

The Availability Balancing List (ABL) (a) consisted of groups of personal (dispositional) and situational characteristics (such as the rated person's intelligence, and the fact that that subjects were involved in an experiment, respectively), and (b) asked each treatment-group participant to give examples of how one or more characteristic in each set might have influenced the rated person's behavior (see Appendices $C, D$, and $E$ ).

In an effort to determine if dissonance phenomena were in fact involved in any effect produced by the $A B L$, the pre- 
commitment-condition $A B L$ contained a statement which informed subjects that "You will have an opportunity to look them [your answers] over later and decide if you want to replace or change any before they are considered final." The ABL's in the other conditions did not contain this statement. If in fact dissonance-type phenomena were responsible for effects produced by the $A B L$, results of subjects attributions in this condition should be significantly different from the other-rater group that expected their answers to be final (and would therefore be expected to make dissonance-reducing attributions). (Appendices $C, D$, and $E$ contain complete $A B L ' s$ for otherraters, pre-commitment condition other-raters, and selfraters, respectively).

The Attribution Survey (AS) was a modified version of the dependent measure used by Storms (1973). This assessed subjects' dispositional versus situational attributions about their conversation partners or themselves (see Appendices F, G, and H for Attribution Surveys for otherraters, pre-commitment other-raters, and self-raters, respectively).

Questionnaires (both the AS and the ABL) were color coded (Blue, Yellow, and Gray) so participants could distinguish which member of the triad they were supposed to rate, and questionnaires were distributed while all members of the triad were present so colors would not be confused. The pre-commitment condition other-rater received the gray 
questionnaire and was termed Person $G$, the self-rater received the blue questionnaire and was termed Person $B$, and the other-rater received the yellow questionnaire and was termed Person Y. All three members of the triad, whether in the self or other conditions, rated the person with the blue questionnaire (Person B) (see TABLE I).

\section{TABLE I}

TYPES AND COLORS OF AVAILABILITY BALANCING

LISTS AND THEIR TARGET SUBJECTS

\begin{tabular}{lcc}
\hline ABL Color & Type of ABL & Rated Subject \\
\hline Blue & Self-rater & Blue \\
Yellow & Other-rater & Blue \\
Gray & pre-commitment other-rater & Blue \\
\hline
\end{tabular}

Finally, a Personal Data Form requested information about age, sex, level of schooling, major field of study, and number of psychology courses completed (see Appendix I).

Procedure. Subjects were recruited from undergraduate courses at Portland State University, primarily on the basis of their ability to come at times which made it possible to form triads.

Triads were randomly assigned to either the control group or the treatment group before they arrived. Upon arrival they entered a room with three comfortable chairs and three tables. Chairs were arranged in circular fashion, and the tables were situated at the back of the room. On 
each chair rested a clipboard and pen, with (a) the Instructions to Participants page and (b) the Informed Consent sheet. Subjects entered the room and were told to "Have a seat where you like." The experimenter then reviewed the Instructions to Participants, and explained that the task was to engage in a short conversation $(10 \mathrm{~min})$ designed for them to "get to know each other", and told participants that they could "Talk about anything you wish, perhaps starting with your names, where you live, and other information you may think is pertinent." subjects were also told that they would be asked to fill out a questionnaire after the conversation regarding their experiences during the exchange. The experimenter then reviewed the Informed Consent page, asked if there were any questions, and requested that subjects give their consent for participation. At this point, the experimenter collected the clipboards with the Informed Consent pages, left the room, and subjects started the conversation. During the following 10minute period, the experimenter randomly assigned each subject in the triad to one of the three questionnaire conditions.

After the 10-minute period, the investigator returned with questionnaires attached to the clipboards and asked treatment-group triads to fill out the $A B L$ followed by the AS. Subjects were told they could use either the tables or remain seated where they were and use the clipboards to fill out the questionnaires. The experimenter went over the 
directions for filling out the $A B L$ with each group, and told them to "please answer all of the questions in their arranged order and then turn your questionnaire over. Don't worry about making corrections or additions as I am interested in your first impressions." When all subjects in each treatment-group triad were finished with both the $A B L$ and the AS, they were asked to make any additions or corrections to the $A B L$ on the back of their questionnaire.

Subjects in the control group were given the instructions and asked to fill out the Attribution survey immediately after the 10-minute period. All participants, when finished with the Attribution Survey, were asked to fill out the Personal Information Form. Finally, all were thanked for their participation, debriefed about the nature of the study, and asked to not speak about the study with others for a two-week period. 
CHAPTER III

RESULTS

A multivariate analysis-of-variance (MANOVA) was used to analyze this mixed design. The ABL/non-ABL difference was the grouping factor (i.e., between-subjects), and Persons was the repeated measures factor. The repeatedmeasures factor was treated as a multivariate profile. The sampling variable in the analysis was triads. This approach is preferable to the ANOVA approach because the subjects-within-groups-by-trials effects are equivalent for all treatment and repeated measures combinations (SYSTAT Manual, 1985, p. 215).

A univariate $\underline{F}$-test revealed no difference in the critical analysis between self vs. other attributions in the control group, $\underline{F}(1,12)=0.128$, n.s. Such a difference, if found, would have replicated previous research on actor-observer differences and provided an indication of the presence of the phenomenon to be modified. Mean percentage of situational attributions for self and other attributions in the control group were 0.468 and 0.478 , respectively, and standard deviations were 0.055 (self) and 0.077 (other). In addition, a univariate $\underline{F}$-test revealed no difference between the other condition vs. the pre-commitment other condition attributions in the control group, $\underline{F}(1,12)=2.575, \mathrm{n} . \mathrm{s}$. 
A univariate $\underline{F}$-test in the self vs. other profile revealed no difference between the $A B L$ condition and the non-ABL condition, $\underline{F}(1,24)=2.598$, n.s. Similarly, a univariate F-test on the other vs. pre-commitment other condition profile showed no difference bsetween the ABL and non-ABL condition, $\underline{F}(1,24)=.382$, n.s.

In a further attempt to obtain the actor-observer differences that would indicate the presence of the phenomenon of interest, a discriminant analysis was performed on the test questions (see Table II for results) to determine whether some items in the Attribution Survey might be better at distinguishing this difference than others. This analysis showed the talkativeness dimension (Items 2 and 7) to be closer to distinguishing the actor-observer difference than other dimensions. A test of the other vs. self groups in the control condition was thus made using only these items. Again, no significant difference was found, $\underline{F}(1,12)=$ 0.196 , n.s. Moreover, further analyses using just these items showed no difference in the $A B L$ by self vs. other attributions $\underline{F}(1,24)=.880, \mathrm{n} . \mathrm{s} .$, and no difference in the $A B L$ by other vs. non-dissonance condition other-attributions, $\underline{F}(1,24)=.037$, n.s.

Normal probability plots of residuals revealed no substantial departure from normality in the above analyses, and plots of residuals against estimates showed no significant departure from homogeneity of variance. Analysis of leverage revealed no variance, indicating that there were 
no extreme scores which might have been influencing the results.

\section{TABLE II}

RESULTS OF DISCRIMINANT ANALYSIS FOR ACTOROBSERVER DIFFERENCES ON ALL ATTRIBUTION SURVEY TEST ITEMS

\begin{tabular}{ccc}
\hline ITEM & $\underline{F}(2,73)$ & $\mathrm{P}$ \\
\hline 1 & 0.209 & 0.812 \\
2 & 1.338 & 0.269 \\
3 & 2.353 & 0.102 \\
4 & 0.333 & 0.718 \\
5 & 1.514 & 0.227 \\
6 & 1.212 & 0.303 \\
7 & 2.048 & 0.136 \\
8 & 1.232 & 0.298 \\
9 & 0.390 & 0.678 \\
10 & 1.658 & 0.198 \\
\hline
\end{tabular}


CHAPTER IV

DISCUSSION

The expected actor-observer difference, in the form of the FAE for observers and a tendency toward situationallydirected attributions for self-raters, was not obtained in the control condition, although both actors and observers tended to make slightly more dispositional attributions than situational. At first glance, this appears to contradict a large body of previous research (Jones, 1976; Jones, 1979; Jones \& Harris, 1967; Miller, Jones \& Hinkle, 1981; Nisbett, 1973; Ross, 1977; Storms, 1973).

An overall effect of the ABL on subjects' attributions was originally expected as well. This would have provided evidence for the relation of actor-observer differences to the availability of information, by showing that when situational data are made more available to observer-raters, and dispositional data are made more available to selfraters, subjects are more likely to make use of this information when making causal attributions.

No $A B L$ main effect was obtained, but there was no reason to expect such an effect because in this group there was no overall bias toward either dispositional or situational factors. In addition, no $A B L-b y-P e r s o n$ interaction was obtained (that is, there was no difference between self 
vs. other or between other vs. precommitment other in the ABL conditions). Again, there was no reason to expect such a difference because no person simple-effect was present in the control condition. Any $A B L$ effect under these circumstances would be unexpected, as the $A B L$ was designed to equalize or balance attributions in conditions where actorobserver differences exist, and in this case, the presence of any such difference was clearly not detected.

In an effort to make sense of the failure to replicate the usual actor-observer attributional differences in the present study, literature relating to conditions where actor-observer differences were reduced or eliminated was inspected. Several types of circumstances have been discussed in reports of recent research which seem to have some relevance to findings of the present study. Four merit consideration.

One, when the salience of the actor's environment is greater than the salience of the actor, behavior may be attributed (by the observer) relatively more situationally than when environmental salience is low (McArthur \& Post, 1977) •

Two, when an actor's behavior is actually dispositionally based (he/she has always behaved this way in the past and intends to do so in the future), the actor is likely to make more dispositionally-based attributions (Monson \& Snyder, 1977).

Three, when the wording of "situational" questions is 
ambiguous, people may use these categories when they aren't sure what caused the behavior, increasing the relative number of situationally-based attributions and creating actor-observer differences. When situational factors are clearly specified and ambiguous attributions are assessed separately, actor-observer differences have been shown to disappear (Goldberg, 1981) (It should be noted that this runs counter to the notion that it is dispositional rather than situational categories that are revised).

Four, when observers are given instructions to empathize with actors, observers make attributions that are "relatively more situational and less dispositional than attributions provided by standard observers" (Regan \& Totten, 1975, p. 850; Gould \& Sigall, 1977).

In the McArthur and Post (1977) study, increasing the salience of the actor's environment (the other people present) on videotape by varying brightness, motion, pattern complexity (of clothing) and contextual novelty, was found to increase the number of situationally-based attributions. It is unlikely that the present study differed from Storms' (1973) study in this respect. If the salience of the experimental room is considered, it might be argued that, because the room was relatively small with three chairs set up in front and three tables set up in back (unusual arrangements for furniture under normal conditions), the environment was made more salient. However, the environment in Storms' study consisted of two actor-conversants being observed by two 
subjects uninvolved in the conversation, and two video cameras trained on the actors. This would seem to present a much more salient environment than the furniture arrangement of the present study and the conversation between the three participants taking place without the presence of the experimenter and yet, actor-observer differences were verified in the storms study.

Monson and Snyder (1977) argue that, under conditions where the actor is aware that his or her behavior has been stable in similar situations and that it will continue to remain stable during similar experiences in the future, actors will tend to make attributions in a dispositional rather than a situational direction. This seems to be a possible explanation for these results, but only because there were no data available in the present study to rule it out. Yet, there seems to be no reason to believe subjects in this experiment would have greater insight into or experience with their dispositions, or more stable crosssituational behavior, than other groups of undergraduate students in similar studies. This type of insight or crosssituational consistency would have to be present if the results were to be explained in this way.

Goldberg (1981) showed that people may make use of ambiguous "situational" categories when they are not sure of the causes of the behavior they are trying to explain, creating actor-observer differences. He found that if situational explanations were made clear in the wording of 
the questionnaire, and unambiguous attributions were assessed separately, these differences were eliminated. This cannot account for the difference between the present experiment and Storms' (1973) classic study since the questions used were virtually identical.

Probably the most likely explanation for this study's failure to replicate the usual actor-observer attributional difference may have to do with results from both Regan and Totten's (1975) as well as Gould and Sigall's studies, which showed that establishing empathy in observers for the actors they were watching produced relatively more situational attributions (and less dispositional attributions) than those produced by observers in other studies. In support of this possibility, it is interesting to note that Storms' (1973) results seem to differ from the present study in the observer groups, not the actor groups. In the current study, both observers' and actors' attributions were similar to actors' attributions in storms.

One major procedural difference which stands out in the present study when compared with other studies (Jones \& Harris, 1967; Miller, Jones, \& Hinkle, 1981; Nisbett, Caputo, Legant, \& Maracek, 1973; Storms, 1973 to name a few), is that none of the observers in these other studies were engaged in the same situation or task as the actors. In the present study, both observers and actors were participants in the conversational situation. It is possible that because observers understood what it was like 
to participate in such a situation, they were able to empathize with the people about whom they were asked to make attributions. If this was the case, it is likely that those observers would make relatively more situational, and less dispositional attributions, therefore eliminating potential actor-observer differences.

Considering this as a reasonable possibility, future research might include a replication of this study with one change: Instead of the pre-commitment condition other-rater participant, a non-participant other-rater could be substituted. In this case the difference between the participant other-rater and the non-participant other-rater could be compared. If empathy is a factor in eliminating actorobserver differences in this study, then the non-participant observer should make more dispositional attributions than the participant observer, and the participant observer's attributions should not differ from the self-rater's.

In conclusion, the present study failed to replicate the well-documented actor-observer attributional difference. This raises questions about how the actor-observer difference has been obtained in the past, particularly if the effect of empathy has eliminated such a difference, because it suggests that this phenomenon may be a consistent result only in experimental settings where actors and observers are kept from engaging in the same task (and therefore from empathizing with each other). This would certainly limit the generalizability and applicability of these types of 
experimental findings to real-world situations. Additional research addressing these questions is necessary, and might provide more concrete information about the circumstances under which such a difference is, and is not, produced. 


\section{REFERENCES}

Bem, D. J., \& McConnell, K. (1970). Testing the selfperception explanation of dissonance phenomena: on the salience of premanipulation attitudes. Journal of Personality and Social Psychology. $1 \overline{4(1), 23-3}$.

Craik, F. I., \& Tulving, E. (1975). Depth of processing and the retention of words in episodic memory. Journal of Experimental Psychology: General, 104(3), $2 \overline{68-294}$.

Einhorn, H. J., \& Hogarth, R. M. (1986). Judging probable cause. Psychological Bulletin, 99(1), 3-19.

Fischhoff, B., Slovic, P., \& Iichtenstein, S. (1978). Fault Trees: Sensitivity of estimated failure probabilities to problem representations. Journal of Experimental Psychology: Human Perception and Performance, $\underline{4}, 330-$ 344 .

Fiske, S. T., \& Taylor, S. E. (1984). Social Cognition. Reading, MA: Wesley.

Funder, D. C. (1982). On the accuracy of dispositional vs. situational attributions, Social Cognition, 1, 205-222.

Goldberg, I. R. (1981). Unconfounding situational attributions from uncertain, neutral, and ambiguous ones: A psychometric analysis of descriptions of oneself and various types of others. Journal of Personality and Social Psychology, $41, \overline{517-552}$.

Gould, R., \& Sigall, H. (1977). The effects of empathy and outcome on attribution: An examination of the divergent-perspectives hypothesis. Journal of Experimental Social Psychology, 13, 480-491.

Hamilton, V. I. (1980). Intuitive psychologist or intuitive lawyer: Alternative models of the attribution process. Journal of Personality and Social Psychology, 39, 767-

Harvey, J. H., Town, J. P., \& Yarkin, K. I. (1981). How fundamental is the fundamental attribution error? Journal of Personality and Social Psychology, 40 (2), 346-349. 
Harvey, J. H., \& Weary, G. (1984). Current issues in attribution theory and research. Annual Review of Psychology, 35, 427-459.

Heider, F. (1958). The psychology of interpersonal relations. New York: Wiley.

Jones, E. E. (1976). How do people perceive the causes of behavior? American Scientist, 64, 300-305.

Jones, E. E. (1979). The rocky road from acts to dispositions. American Psychologist, 34, 107-117.

Jones, E. E., \& Harris, V. A. (1967). The attribution of attitudes. Journal of Experimental Social Psychology, $\underline{3}, 1-24$.

McArthur, L. Z., \& Post, D. (1977). Figural emphasis and person perception. Journal of Experimental Social Psychology, 13, $\overline{520-535}$.

Miller, A. G., Jones, E. E., \& Hinkel, S. (1981). A robust attribution error in the personality domain. Journal of Experimental Social Psycholgy, 17, 587-600.

Monson, T. C., \& Snyder, M. (1977). Actors, observers, and the attribution process: Toward a reconceptualization. Journal of Experimental Social Psychology, 13, 89-111.

Nisbett, R. E., Caputo, C., Legant, P., \& Maracek, J. (1973). Behavior as seen by the actor and as seen by the observer. Journal of Personality and Social Psychology, $\underline{27}, 154-16 \overline{4}$.

Nisbett, R. E., \& Ross, L. (1980). Human inference: Strategies and shortcomings of social judgment. Englewood cliffs, NJ: Prentice-Hall, Inc.

Orne, M. (1962). On the social psychology of the psychological experiment. American Psychologist, 17, $776-783$.

Regan, D. T., \& Totten, J. (1975). Empathy and attribution: Turning observers into actors. Journal of Personality and Social Psychology, 13, 480-491.

Ross, L. (1977). The intuitive psychologist and his shortcomings: Distortions in the attribution process. In L. Berkowitz (Ed.), Advances in Experimental Social Psychology (Vo1. 10). New York: ACademic Press. 
Storms, M. D. (1973). Videotape and the attribution process: Reversing actors and observers points of view. Journal of Personality and Social Psychology, 27(2), 165-175.

SYSTAT Manual. (1985). Evanston, IL: SYSTAT, Inc.

Taylor, S. E., \& Fiske, S. T. (1975). Point of view and perceptions of causality. Journal of Personality and Social Psychology, $32(3), \overline{439-445}$.

Tversky, A., \& Kahneman, D. (1974). Judgment under uncertainty: Heuristics and biases. Science, 185, 1124-1131.

Wixon, D. R., \& Laird, J. D. (1976). Awareness and attitude change in the forced-compliance paradigm: The importance of when. Journal of Personality and

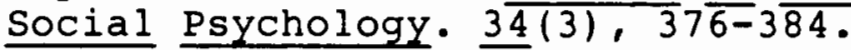




\section{APPENDIX A}

INFORMED CONSENT SHEET

I , - hereby agree to serve as a subject in a research project on Interpersonal Relationships conducted by Carla A. Green.

I understand that the study involves talking with two other people and filling out a questionnaire.

I understand that possible risks to me associated with this study are loss of time or interest during participation.

It has been explained to me that the purpose of the study is to learn about interpersonal relationships.

I may not receive any direct benefit from participation in this study, but my participation may help to increase knowledge which may benefit others in the future.

Carla A. Green has offered to answer any questions I may have about the study. I have been assured that all information I give will be kept confidential and that the identity of all subjects will remain anonymous.

I understand that I am free to withdraw from participation in this study at any time without jeopardizing my relationship with Portland State University or the grade in my class. 
I have read and understand the foregoing information.

Date Signature

If you experience problems that are the result of your participation in this study, please contact Director of Sponsored Research, Office of Graduate Studies and Research, 105 Neuberger Hall, Portland State University, 229-3423. 


\section{APPENDIX B}

\section{INSTRUCTIONS TO PARTICIPANTS}

This is a study in an area of social psychology called Interpersonal Relations. More specifically, I'm interested in people getting to know each other. The three of you will be having a short first conversation with each other, lasting about ten minutes. You may talk about anything you wish, perhaps starting with your names, where you live and other information you may think is pertinent. At the end of your discussion I will ask you to fill out a questionnaire regarding your experiences in the conversation. 


\begin{abstract}
APPENDIX C
AVAILABILITY BALANCING LIST FOR OTHER-RATERS
\end{abstract}

For the purposes of this questionnaire, please use the following abbreviations:

PERSON $B=$ Person with blue questionnaire PERSON $G=$ Person with gray questionnaire

The following are characteristics which may have had an influence or effect on the behavior of your conversation partners.

For each numbered item, provide an example of how one or more of the characteristics named influenced Person B's behavior. (You may give short or longer answers, as long as you do not exceed the space provided for you.)

Here are two samples of what your answers might be like:

a) Person B's political beliefs.

example: Person B seemed to have very strong beliefs about the differences between Democrats and Republicans, and when she found out I was a Democrat, she acted as if I wasn't worth talking to anymore, and she ignored me.

b) Your own political beliefs.

example: My own political beliefs can be considered somewhat strong and I've been told that I can be abrasive about them at times. It is possible that my abrasiveness could have made Person B less willing to converse with me.

INFLUENTIAL PERSONAL CHARACTERISTICS OF PERSON B

1. Person B's Intelligence and/or Personal Skills.

2. Person B's general Character, Personality, and/or Personal Style. 
3. Person B's specific Attitudes, Motivation, and/or Mood.

4. The Sex and/or Age of Person B.

5. Person B's cultural background (i.e. religion, race, and/or ethnic groupl.

6. Person B's level of education, social class and/or occupation.

INFLUENTIAL CHARACTERISTICS OF THE EXPERIMENT

7. The fact that this is an Experiment, including the presence of the investigator. 
8. The Topics of conversation, and the fact that you were told to "Get to know" each other.

9. The lack of Previous Association between the three of you.

INFLUENTIAL PERSONAL CHARACTERISTICS OF YOURSELF AND PERSON G ON THE BEHAVIOR OF PERSON B

10. Your own and Person G's Intelligence and/or Personal Skills.

11. Your own and Person G's general Character, Personality, and/or Personal Style.

12. Your own and Person G's specific Attitudes, Motivation, and/or Mood. 
13. Your own and Person G's Sex and/or Age.

14. Your own and Person G's Behavior.

15. Your own and Person G's cultural background (i.e. religion, race, and/or ethnic group).

16. Your own and Person G's level of education, social class and/or occupation.

INFLUENTIAL CHARACTERISTICS OF THE SETTING

17. Time of day and/or Temperature of the room. 
18. Comfortableness and Layout of the room and its Furnishings.

19. Room Lighting and Color of the Room and/or Furnishings 
AVAILABILITY BALANCING LIST FOR PRE-COMMITMENT OTHER-RATERS

For the purposes of this questionnaire, please use the following abbreviations:

PERSON $B=$ Person with blue questionnaire

PERSON $Y=$ Person with yellow questionnaire

The following are characteristics which may have had an influence or effect on the behavior of your conversation partners.

For each numbered item, provide an example of how one or more of the characteristics named influenced Person B's behavior. (You may give short or longer answers, as long as you do not exceed the space provided for you.) The examples you generate now will be tentative. You will have an opportunity to look them over later and decide if you want to replace or change any before they are considered final.

Here are two samples of what your answers might be like:

a) Person B's political beliefs.

example: Person $B$ seemed to have very strong beliefs about the differences between Democrats and Republicans, and when she found out I was a Democrat, she acted as if I wasn't worth talking to anymore, and she ignored me.

b) Your own political beliefs.

example: My own political beliefs can be considered somewhat strong and I've been told that I can be abrasive about them at times. It is possible that my abrasiveness could have made Person $B$ less willing to converse with me.

INFLUENTIAL PERSONAL CHARACTERISTICS OF PERSON B

1. Person B's Intelligence and/or Personal Skills. 
2. Person B's general Character, Personality, and/or Personal Style.

3. Person B's specific Attitudes, Motivation, and/or Mood.

4. The Sex and/or Age of Person B.

5. Person B's cultural background (i.e. religion, race, and/or ethnic group).

6. Person B's level of education, social class and/or occupation. 
INFLUENTIAL CHARACTERISTICS OF THE EXPERIMENT

7. The fact that this is an Experiment, including the presence of the investigator.

8. The Topics of conversation, and the fact that you were told to "Get to know" each other.

9. The lack of Previous Association between the three of you.

INELUENTIAL PERSONAL CHARACTERISTICS OF YOURSELF AND PERSON $\underline{Y}$ ON THE BEHAVIOR OF PERSON B

10. Your own and Person $Y^{\prime}$ s Intelligence and/or Personal Skills.

11. Your own and Person Y's general Character, Personality, and/or Personal style. 
12. Your own and Person Y's specific Attitudes, Motivation, and/or Mood.

13. Your own and Person Y's Sex and/or Age.

14. Your own and Person Y's Behavior.

15. Your own and Person Y's cultural background (i.e. religion, race, and/or ethnic group).

16. Your own and Person Y's level of education, social class and/or occupation. 
INFLUENTIAL CHARACTERISTICS OF THE SETTING

17. Time of day and/or Temperature of the room.

18. Comfortableness and Layout of the room and its Furnishings.

19. Room Lighting and Color of the Room and/or Furnishings 


\section{APPENDIX E}

\section{AVAILABILITY BALANCING LIST FOR SELF-RATERS}

For the purposes of this questionnaire, please use the following abbreviations:

\section{PERSON $Y=$ Person with yellow questionnaire PERSON G = Person with gray questionnaire}

The following are characteristics which may have had an influence or effect on your behavior during the conversation. Please consider only your behavior when filling out the questionnaire.

For each numbered item, provide an example of how one or more of the characteristics named influenced your own behavior. (You may give short or longer answers, as long as you do not exceed the space provided for you.l

Here are two samples of what your answers might be like:

a) Your own political beliefs. example: My own political somewhat strong and I've been told that I can be abrasive about them at times. It is possible that my abrasiveness could have made person $Y$ and Person $G$ less willing to converse with me.

b) Person $Y$ and/or Person G's political beliefs. example: Person $G$ seemed to have very strong beliefs about the differences between Democrats and Republicans, and when she found out I was a Democrat, she acted as if I wasn't worth talking to anymore, and she ignored me.

YOUR OWN INFLUENTIAL PERSONAL CHARACTERISTICS

1. Your Intelligence and/or Personal Skills. 
2. Your general Character, Personality, and/or Personal Style.

3. Your specific Attitudes, Motivation, and/or Mood.

4. Your Sex and/or Age.

5. Your cultural background (i.e. religion, race, and/or ethnic group).

6. Your level of education, social class and/or occupation. 
7. The fact that this is an Experiment, including the presence of the investigator.

8. The Topics of conversation, and/or the fact that you were told to "Get to Know" each other.

9. The lack of Previous Association between the three of you.

INFLUENTIAL PERSONAL CHARACTERISTICS OF PERSON $\underline{Y}$ AND PERSON G ON YOUR OWN BEHAVIOR

10. Person Y's and/or Person G's Intelligence and/or Personal Skills.

11. Person $Y^{\prime}$ 's and/or Person G's general Character, Personality, and/or Personal Style. 
12. Person $Y^{\prime}$ s and/or Person G's specific Attitudes, Motivation, and/or Mood.

13. Person Y's and/or Person G's Sex and/or Age.

14. Person Y's and/or Person G's behavior.

15. Person Y's and/or Person G's cultural background (i.e. religion, race, and/or ethnic group).

16. Person Y's and/or Person G's level of education, social class, and/or occupation. 


\section{INFLUENTIAL CHARACTERISTICS OF THE SETTING}

17. Time of day and or Temperature of the room.

18. Comfortableness and Layout of the room and its Furnishings.

19. Room Lighting and Color of the Room and/or Furnishings. 


\section{APPENDIX F}

\section{ATTRIBUTION SURVEY FOR OTHER-RATERS}

For the purposes of this questionnaire, please remember the following abbreviations:

PERSON $B=$ Person with blue questionnaire

PERSON $G=$ Person with gray questionnaire

When you fill out the following questionnaire, please consider only the behavior of Person B. For each three part question on the following pages, please rate the behavior of person $B$ along the following dimensions: friendliness, talkativeness, nervousness, dominance and listening. Then for each of these five behaviors, indicate how much influence you think the following factors had in causing that behavior.

Please circle the number which most closely describes your feelings about your conversation partner (Person B); ones are approximately equal across all questions as are nines etc.

1a. To what extent did Person $B$ behave in a friendly, warm manner?

\begin{tabular}{|c|c|c|c|c|c|c|c|c|}
\hline $\begin{array}{l}1 \\
\text { extremely } \\
\text { friendly }\end{array}$ & 2 & 3 & 4 & 5 & 6 & 7 & 8 & $\begin{array}{l}9 \\
\text { extremely } \\
\text { unfriendly }\end{array}$ \\
\hline
\end{tabular}

b. How important were personal and personality characteristics of Person $B$ in causing his/her friendly, warm behavior?

$\begin{array}{llllllllll}\text { extremely } & 1 & 2 & 3 & 4 & 5 & 6 & 7 & 8 & \begin{array}{c}9 \\ \text { extremely } \\ \text { important }\end{array} \\ \text { unimportant }\end{array}$

c. How important were characteristics of the situation (including yourself and Person $G$ ) in causing his/her friendly, warm behavior?

extremely

123

important

$\begin{array}{llllll}4 & 5 & 6 & 7 & 8 & 9\end{array}$

extremely

unimportant 
2a. To what extent did Person $B$ behave in a talkative manner?

extremely $\begin{array}{lllllllll}1 & 2 & 3 & 4 & 5 & 6 & 7 & 8 & 9\end{array}$ talkative

extremely non-talkative

b. How important were personal and personality characteristics of Person B in causing his/her talkative behavior?

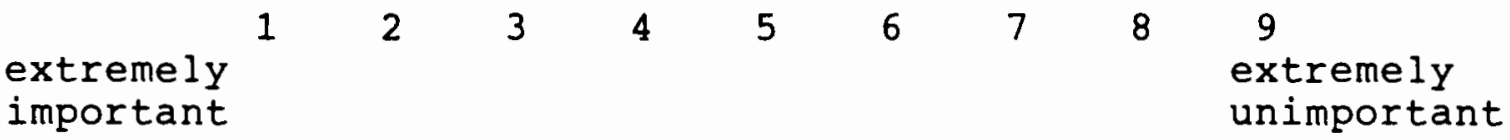

c. How important were characteristics of the situation (including yourself and Person $G$ ) in causing his/her talkative behavior?

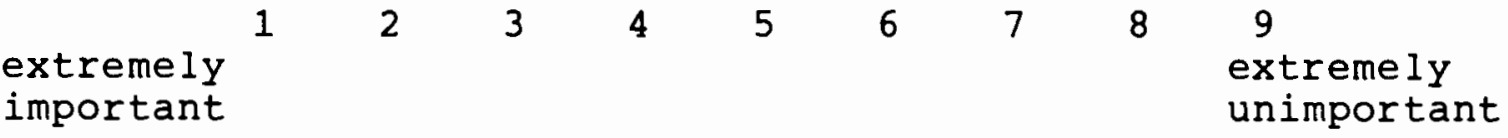

3a. To what extent did Person $B$ behave in a nervous manner?

extremely

$\begin{array}{lllllllll}1 & 2 & 3 & 4 & 5 & 6 & 7 & 8 & 9\end{array}$

nervous

extremely comfortable

b. How important were personal and personality characteristics of Person $B$ in causing his/her nervous or comfortable behavior?

$\begin{array}{llllllllll}\text { extremely } & 1 & 2 & 3 & 4 & 5 & 6 & 7 & 8 & \begin{array}{c}9 \\ \text { extremely } \\ \text { unportant }\end{array} \\ \text { important }\end{array}$

c. How important were characteristics of the situation (including yourself and Person $G$ ) in causing his/her nervous or comfortable behavior?

extremely

$\begin{array}{lllllllll}1 & 2 & 3 & 4 & 5 & 6 & 7 & 8 & 9\end{array}$

important

extremely unimportant 
4a. To what extent did Person $B$ behave in a dominant manner?

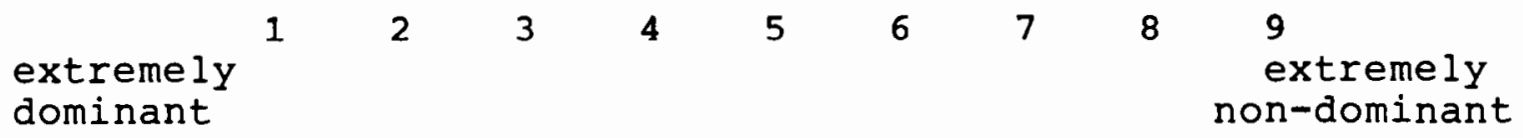

b. How important were personal and personality characteristics of Person $B$ in causing his/her dominant behavior?

extremely

$\begin{array}{lllllllll}1 & 2 & 3 & 4 & 5 & 6 & 7 & 8 & 9\end{array}$

important

extremely

unimportant

c. How important were characteristics of the situation (including yourself and Person $G$ ) in causing his/her dominant behavior?

extremely

$\begin{array}{lllllllll}1 & 2 & 3 & 4 & 5 & 6 & 7 & 8 & 9\end{array}$

important

extremely unimportant

5a. To what extent did Person B behave as a good listener?

extremely

$\begin{array}{llllllllll}1 & 2 & 3 & 4 & 5 & 6 & 7 & 8 & 9\end{array}$

good listener

extremely

bad listener

b. How important were personal and personality characteristics of Person B in causing his/her listening behavior?

extremely

$\begin{array}{lllllllll}1 & 2 & 3 & 4 & 5 & 6 & 7 & 8 & 9\end{array}$

important

extremely unimportant

c. How important were characteristics of the situation (including yourself and Person $G$ ) in causing his/her listening behavior?

extremely $\begin{array}{lllllllll}1 & 2 & 3 & 4 & 5 & 6 & 7 & 8 & 9\end{array}$ important unimportant 


\section{APPENDIX G}

\section{ATTRIBUTION SURVEY FOR PRE-COMMITMENT OTHER-RATERS}

For the purposes of this questionnaire, please remember the following abbreviations:

$$
\begin{aligned}
& \text { PERSON } B=\text { Person with blue questionnaire } \\
& \text { PERSON } Y=\text { Person with yellow questionnaire }
\end{aligned}
$$

When you fill out the following questionnaire, please consider only the behavior of Person B. For each three part question on the following pages, please rate the behavior of person $B$ along the following dimensions: friendliness, talkativeness, nervousness, dominance and listening. Then for each of these five behaviors, indicate how much influence you think the following factors had in causing that behavior.

Please circle the number which most closely describes your feelings about your conversation partner (Person B); ones are approximately equal across all questions as are nines etc.

1a. To what extent did Person B behave in a friendly, warm manner?

extremely

$\begin{array}{lllllllll}1 & 2 & 3 & 4 & 5 & 6 & 7 & 8 & 9\end{array}$

friendly

extremely unfriendly

b. How important were personal and personality characteristics of Person $B$ in causing his/her friendly, warm behavior?

extremely

$\begin{array}{lllllllll}1 & 2 & 3 & 4 & 5 & 6 & 7 & 8 & 9\end{array}$

important

extremely

unimportant

c. How important were characteristics of the situation (including yourself and Person $Y$ ) in causing his/her friendly, warm behavior?

extremely $\begin{array}{lllllllll}1 & 2 & 3 & 4 & 5 & 6 & 7 & 8 & 9\end{array}$

important

extremely unimportant 
2a. To what extent did Person B behave in a talkative manner?

$\begin{array}{llllllllll}\underset{\text { extremely }}{\text { talkative }} & 1 & 2 & 3 & 4 & 5 & 6 & 7 & 8 & \begin{array}{c}9 \\ \text { extremely } \\ \text { non-talkative }\end{array}\end{array}$

b. How important were personal and personality characteristics of Person B in causing his/her talkative behavior?

extremely

$\begin{array}{lllllllll}1 & 2 & 3 & 4 & 5 & 6 & 7 & 8 & 9\end{array}$

important

extremely

unimportant

c. How important were characteristics of the situation (including yourself and Person $Y$ ) in causing his/her talkative behavior?

$\begin{array}{ccccccccccc}\begin{array}{l}\text { extremely } \\ \text { important }\end{array} & 1 & 2 & 3 & 4 & 5 & 6 & 7 & 8 & \begin{array}{c}9 \\ \text { extremely } \\ \text { unimportant }\end{array}\end{array}$

3a. To what extent did Person $B$ behave in a nervous manner?

extremely

$\begin{array}{lllllllll}1 & 2 & 3 & 4 & 5 & 6 & 7 & 8 & 9\end{array}$

nervous

extremely comfortable

b. How important were personal and personality characteristics of Person $B$ in causing his/her nervous or comfortable behavior?

extremely

$\begin{array}{lllllllll}1 & 2 & 3 & 4 & 5 & 6 & 7 & 8 & 9\end{array}$

important

extremely

unimportant

c. How important were characteristics of the situation (including yourself and Person $Y$ ) in causing his/her nervous or comfortable behavior?

extremely

$\begin{array}{lllllllll}1 & 2 & 3 & 4 & 5 & 6 & 7 & 8 & 9\end{array}$

important

extremely unimportant

4a. To what extent did Person $B$ behave in a dominant manner? extremely $\begin{array}{lllllllll}1 & 2 & 3 & 4 & 5 & 6 & 7 & 8 & 9\end{array}$ dominant 
b. How important were personal and personality characteristics of Person B in causing his/her dominant behavior?

$\begin{array}{llllllllll}\text { extremely } & 1 & 2 & 3 & 4 & 5 & 6 & 7 & 8 & \begin{array}{c}9 \\ \text { extremely } \\ \text { important }\end{array} \\ & & & & & & & & & \\ \text { unimportant }\end{array}$

c. How important were characteristics of the situation (including yourself and Person $Y$ ) in causing his/her dominant behavior?

$\begin{array}{llllllllll} & 1 & 2 & 3 & 4 & 5 & 6 & 7 & 8 & \begin{array}{c}9 \\ \text { extremely } \\ \text { important }\end{array} \\ \text { impormertant }\end{array}$

5a. To what extent did Person B behave as a good listener?

extremely $\begin{array}{lllllllll}1 & 2 & 3 & 4 & 5 & 6 & 7 & 8 & 9\end{array}$

good listener extremely bad listener

b. How important were personal and personality characteristics of Person B in causing his/her listening behavior?

$\begin{array}{llllllllll}\text { extremely } & 1 & 2 & 3 & 4 & 5 & 6 & 7 & 8 & \begin{array}{c}9 \\ \text { extremely } \\ \text { important }\end{array} \\ & & & & & & & & & \end{array}$

c. How important were characteristics of the situation (including yourself and Person $Y$ ) in causing his/her listening behavior?

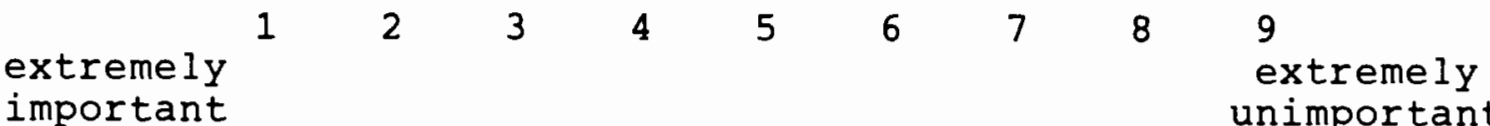




\section{APPENDIX H}

\section{ATTRIBUTION SURVEY FOR SELF-RATERS}

For the purposes of this questionnaire, please remember the following abbreviations:

\section{PERSON $Y=$ Person with yellow questionnaire \\ PERSON $G=$ Person with gray questionnaire}

When you fill out the following questionnaire, please consider just your own behavior. For each three part question on the following pages, please rate your behavior along the following dimensions: friendliness, talkativeness, nervousness, dominance and listening. Then for each of these five behaviors, indicate how much influence you think the following factors had in causing that behavior.

Please circle the number which most closely describes your feelings about your behavior; ones are approximately equal across all questions as are nines etc.

1a. To what extent did you behave in a friendly, warm manner?

$\begin{array}{llllllllll} & 1 & 2 & 3 & 4 & 5 & 6 & 7 & 8 & \begin{array}{c}9 \\ \text { extremely } \\ \text { extremely }\end{array} \\ \text { friendly } & & & & & & & & & \end{array}$

b. How important were your personal and personality characteristics in causing your friendly, warm behavior?

extremely

$\begin{array}{lllllllll}1 & 2 & 3 & 4 & 5 & 6 & 7 & 8 & 9\end{array}$

important

extremely

unimportant

c. How important were characteristics of the situation (including Person $G$ and Person $Y$ ) in causing your friendly, warm behavior?

extremely

$\begin{array}{lllllllll}1 & 2 & 3 & 4 & 5 & 6 & 7 & 8 & 9\end{array}$

important

extremely unimportant

2a. To what extent did you behave in a talkative manner?

extremely

$\begin{array}{lllllllll}1 & 2 & 3 & 4 & 5 & 6 & 7 & 8 & 9\end{array}$

talkative

extremely non-talkative 
b. How important were your personal and personality characteristics of in causing your talkative behavior?

$\begin{array}{llllllllll}\text { extremely } & 1 & 2 & 3 & 4 & 5 & 6 & 7 & 8 & \begin{array}{c}9 \\ \text { extremely } \\ \text { important }\end{array} \\ \text { unimportant }\end{array}$

$\begin{array}{llllllllll}\text { extremely } & 1 & 2 & 3 & 4 & 5 & 6 & 7 & 8 & \begin{array}{c}9 \\ \text { extremely } \\ \text { important }\end{array} \\ \text { unimportant }\end{array}$

c. How important were characteristics of the situation (including Person $G$ and Person $Y$ ) in causing your talkative behavior?

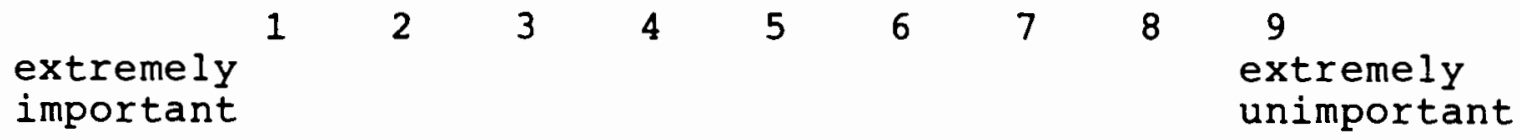

3a. To what extent did you behave in a nervous manner?

$\begin{array}{llllllllll} & & 2 & 3 & 4 & 5 & 6 & 7 & 8 & 9\end{array}$

nervous

extremely comfortable

b. How important were your personal and personality characteristics in causing your nervous or comfortable behavior?

$\begin{array}{llllllllll}\text { extremely } & 1 & 2 & 3 & 4 & 5 & 6 & 7 & 8 & \begin{array}{c}9 \\ \text { extremely } \\ \text { unimportant }\end{array} \\ \text { important } & & & & & & & & & \end{array}$

c. How important were characteristics of the situation (including Person $G$ and Person $Y$ ) in causing your nervous or comfortable behavior?

$\begin{array}{llllllllll}\text { extremely }_{\text {important }} & & 2 & 3 & 4 & 5 & 6 & 7 & 8 & 9 \\ \text { extremely } \\ \text { unimportant }\end{array}$

4a. To what extent did you behave in a dominant manner?

dominant

non-dominant

b. How important were your personal and personality characteristics in causing your dominant behavior?

$\begin{array}{llllllllll}1 & 2 & 3 & 4 & 5 & 6 & 7 & 8 & 9\end{array}$

extremely

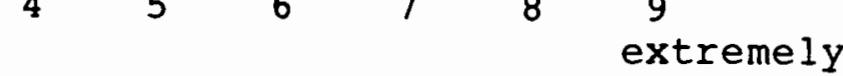

important

unimportant 
c. How important were characteristics of the situation (including Person $G$ and Person $Y$ ) in causing your dominant behavior?

$\begin{array}{llllllllll}\text { extremely }_{\text {important }} & 1 & 2 & 3 & 4 & 5 & 6 & 7 & 8 & \begin{array}{c}9 \\ \text { extremely } \\ \text { unimportant }\end{array}\end{array}$

5a. To what extent did you behave as a good listener?

$\begin{array}{lllllllll}\quad 1 & 2 & 3 & 4 & 5 & 6 & 7 & 8 & \begin{array}{l}9 \\ \text { extremely } \\ \text { bad listener }\end{array} \\ \text { good listener } & & & & & & & & \end{array}$

b. How important were your personal and personality characteristics in causing your listening behavior?

extremely

$\begin{array}{lllllllll}1 & 2 & 3 & 4 & 5 & 6 & 7 & 8 & 9\end{array}$

important

extremely

unimportant

c. How important were characteristics of the situation (including Person $G$ and Person $Y$ ) in causing your listening behavior?

extremely

$\begin{array}{lllllllll}1 & 2 & 3 & 4 & 5 & 6 & 7 & 8 & 9\end{array}$

important

extremely unimportant 


\section{APPENDIX I}

\section{PERSONAL DATA FORM}

It would be very helpful if you would provide the following information:

Age :

Sex :

Year in school (if student):

Major field of study:

Approximately how many psychology classes have you taken?

Have you done any graduate work?

If so, in what area?

How many years? 